\title{
Relationship between skeletal malocclusion and dental anomalies in Nepalese population
}

\author{
Dr Bashu Dev Pant,' Dr Anjana Rajbhandari,2 Dr Resina Pradhan,3 Dr Manju Bajracharya
}

13.4Assistant Professor, 2Professor and Head, Department of Orthodontics, Peoples Dental College and Hospital, Kathmandu, Nepal

Correspondence: Dr Bashu Dev Pant; Email: pantbasudev50@yahoo.com

\section{ABSTRACT}

Introduction: Teeth eruption is important for the development of alveolar process which increases vertical height of the face and third molar is the last tooth to erupt in the oral cavity after birth. The aim of this study was to determine relationship between skeletal malocclusion and dental anomalies in Nepalese population.

Materials \& Method: A sample of 170 patients with agenesis of at least one third molar was divided into four groups according to the third-molar agenesis pattern. Panoramic radiographs, lateral cephalograph and cast models were used to determine the skeletal malocclusion and associated dental anomalies. The Pearson chi-square test was used for stastical analysis.

Result: Among 170 patients more than half of the patients were female with the average age being $18.15 \pm 3.64$ years. Majority of the patients had Class I skeletal malocclusion followed by Class II and III but on group wise comparison of patients with different skeletal patterns Class I skeletal malocclusion had highest prevalence of dental anomalies followed by Class III and Class II malocclusion.

Conclusion: Prevalence of third-molar agenesis was more in skeletal class I malocclusion followed by class II and III but skeletal Class I malocclusions had more dental anomalies followed by class III and class II malocclusion.

Keywords: Hypodontia, Skeletal malocclusion, Tooth agenesis.

\section{INTRODUCTION}

Tooth agenesis is the congenital absence of at least one permanent tooth, because it never formed.' The order of decreasing frequency of agenesis is third molar, mandibular second premolar, and maxillary lateral incisor, suggesting that it is the most distal tooth in each group that disappears. ${ }^{2.3}$ Ageneses do not appear in isolation, ${ }^{4}$ they are usually associated with development anomalies such as delayed tooth formation, late exfoliation of deciduous teeth, retention of deciduous teeth, agenesis of other teeth, poor development of the alveolar bone and crownsize reduction, particularly crown size reduction of the upper lateral incisors and second premolar. Garn ${ }^{5}$ reported that when a third molar is absent, agenesis of the remaining teeth is thirteen times more likely to occur and frequency of third molar agenesis ranges from $14 \%$ to $51.1 \% .^{6}$

The third molar is a tooth that develops after birth and is also the last tooth to erupt. It has variability in the time of formation, varying crown and root morphology, and its varying presence or absence in the oral cavity. ${ }^{7}$ Variations in tooth morphology are associated with tooth agenesis, including reduced mesiodistal crown diameter and conical or tapered crowns. ${ }^{8}$ Corresponding contralateral teeth are often accompanied by imperfect morphologic formation.?

The alveolar process, the portions of the mandible and the maxilla that surround and support the dentition, dependent on crown completion and root formation. ${ }^{10}$ Third molars are important in assessing the dental age of juveniles and also provide forensic specimens. ${ }^{4,11}$ Orthodontic treatment planning is also affected by third molar agenesis, especially when arch distalization is planned.

\section{MATERIALS AND METHOD}

The subjects for the study were selected from Pretreatment records of patients who had undergone various orthodontic treatments in the Department of Orthodontics and Dentofacial Orthopedics, Peoples Dental College and Hospital Kathmandu, Nepal. 


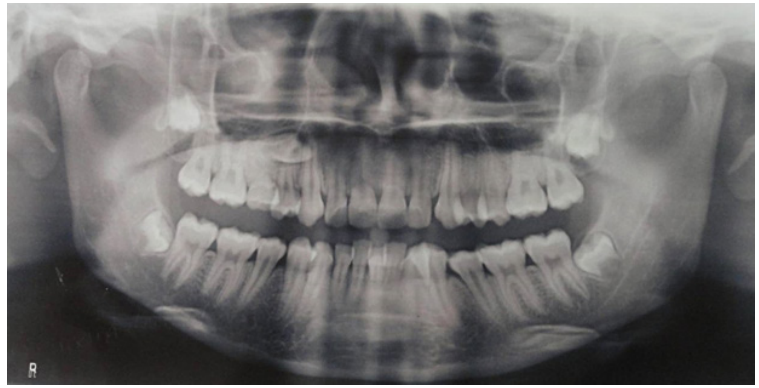

Figure 1: Orthopantomograph

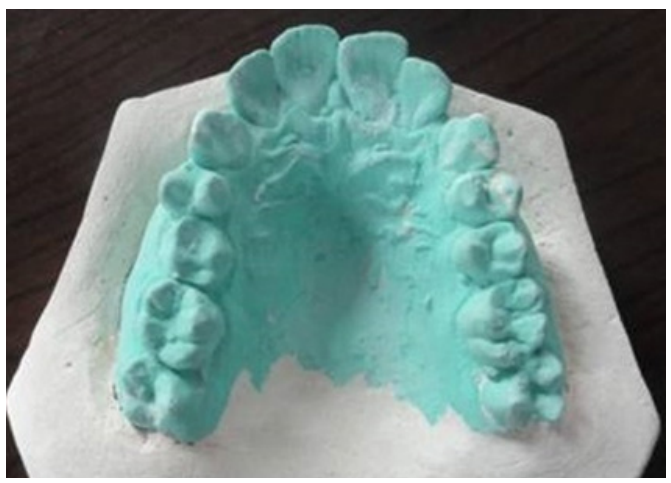

Figure 3: Study Model

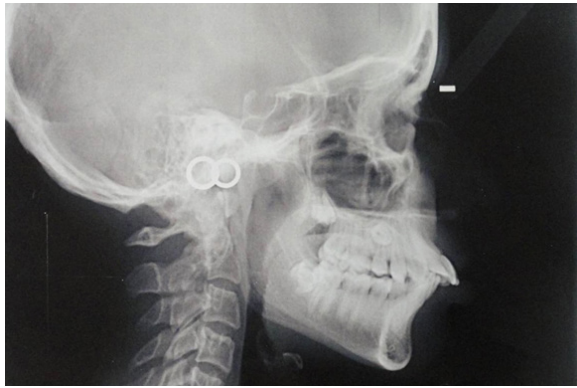

Figure 2: Lateral Cephalogram

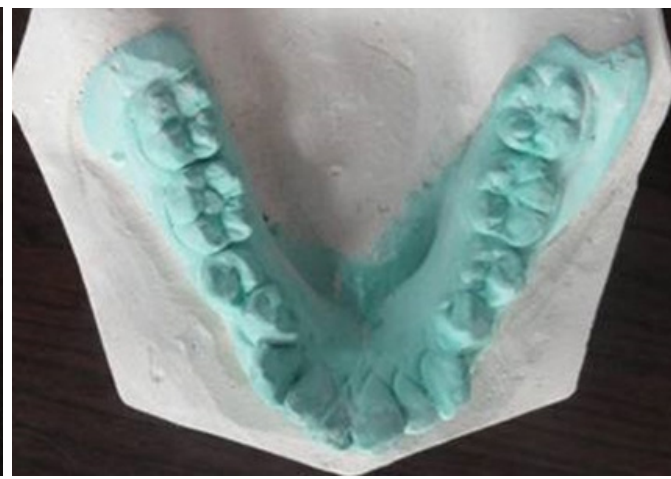

analysis. The numerical variables were summarized with the help of mean, median, standard deviation and range. The categorical variables were expressed in frequency and percentages. The Pearson chisquare test was used to determine the differences in the distribution of the associated dental anomalies between the group, sex and skeletal malocclusion and level of significance is set at $5 \%$.

\section{RESULT}

Among 170 patients more than half of the patients were female. Majority of the patients had Class I skeletal malocclusion followed by Class II and III (Table $2)$. The results showed that Class I skeletal malocclusion had highest prevalence of dental anomalies followed by Class III and Class II malocclusion (Table 3). This difference in proportion among the patients reached statistical significance with $p$ value less than 0.001 . Thus, there is a significant association between skeletal malocclusion and occurrence of dental anomalies. The results are summarized in tables 1, 2, 3 and 4 .

Table 1. Age distribution and association of dental anomalies between genders

\begin{tabular}{|c|c|c|c|c|c|}
\hline \multirow{2}{*}{ Gender } & \multirow{2}{*}{ Number } & \multicolumn{2}{|c|}{ Dental Anomalies } & $\begin{array}{c}\text { Chi Squared } \\
\text { Value }\end{array}$ & \multirow{2}{*}{ P value } \\
\cline { 3 - 4 } & Presence & Absence & \multirow{2}{*}{0} & \multirow{2}{*}{0.654} & \multirow{2}{*}{0.419} \\
\hline Male & $55(32.4 \%)$ & $18(28.6 \%)$ & $37(34.6 \%)$ & \\
\hline Female & $115(67.6 \%)$ & $45(71.4 \%)$ & $70(65.4 \%)$ & $0.65)$ \\
\hline Total & $170(100 \%)$ & $63(37.1 \%)$ & $107(62.9 \%)$ & & \\
\hline
\end{tabular}


Table 2: Characteristics of the skeletal malocclusion and third molars agenesis

\begin{tabular}{|c|c|c|c|}
\hline Characteristics & Categories & Number & Percent \\
\hline \multirow{3}{*}{ Skeletal Malocclusion } & Class I & 90 & $52.9 \%$ \\
\cline { 2 - 4 } & Class II & 44 & $25.9 \%$ \\
\cline { 2 - 4 } & Class III & 36 & $21.2 \%$ \\
\hline
\end{tabular}

Table 3: Association of skeletal malocclusion with presence of dental anomalies

\begin{tabular}{|c|c|c|c|c|}
\hline \multirow{2}{*}{ Skeletal Malocclusion } & \multicolumn{2}{|c|}{ Dental Anomalies } & \multirow{2}{*}{ Chi Squared Value } & \multirow{2}{*}{ P value } \\
\cline { 2 - 3 } & Presence & Absence & & \\
\hline Class I & $27(42.9 \%)$ & $63(58.9 \%)$ & & $<0.001^{*}$ \\
\hline Class II & $11(17.5 \%)$ & $33(30.8 \%)$ & 20.853 & \\
\hline Class III & $25(39.7 \%)$ & $11(10.3 \%)$ & & \\
\hline Total & $63(100 \%)$ & $107(100 \%)$ & & \\
\hline
\end{tabular}

* Statistically Significant

Table 4: Association of presence of dental anomalies with skeletal malocclusion - Odds ratio estimates

\begin{tabular}{|c|c|c|c|c|c|}
\hline Skeletal Malocclusion & Odds Ratio & Lower Estimate & Upper Estimate & $\begin{array}{c}\text { Chi Squared } \\
\text { Value }\end{array}$ & P value \\
\hline Class I (Reference) & - & - & - & - & - \\
\hline Class II & 1.286 & 0.567 & 2.913 & 0.363 & 0.546 \\
\hline Class III & 0.182 & 0.081 & 0.436 & 16.506 & $<0.001^{*}$ \\
\hline
\end{tabular}

* Statistically Significant

\section{DISCUSSION}

Third molar is a tooth that develops after birth and also the last tooth to erupt. It is characterized by the variability in the time of its formation, its widely varying crown and root morphology, and its varying presence or absence in the oral cavity. The purpose of this study was to determine the association between skeletal malocclusion and dental anomalies in Nepalese population. One hundred seventy sample of adolescent patients aged between 13 to 25 years with agenesis of at least one third molar was selected from the files of orthodontic patients undergoing treatment in Department of Orthodontics, Peoples dental college and hospital, Kathmandu, Nepal.

In this study minimum age was set at 13 years because third molar crypt formation starts at 3 to 4 years of age, calcification begins from 7 to 10 years, crown calcification completes at 12 to 16 years of age and eruption occurs between 17 to 25 years of age..$^{12,13}$ Upper age limit was set at 25 years because upto this age complete eruption of $3^{\text {rd }}$ molar occurs in the oral cavity. If any patient had undergone surgical removal of a third molar, those patients were excluded from the study. The clinical implications of the associated dental anomalies are relevant, since early detection of a single dental anomaly may call the attention of professionals to the possible development of other associated anomalies in the same patient or in the family, allowing timely orthodontic intervention.

Females presented a higher prevalence of third molar agenesis than males. As the dimensions of dental arch of females were generally smaller than males and growth of maxilla and mandible in females were slower after 12-13 years but in case of male growth continues until age of 16 years. ${ }^{14}$ Racial variations, dietary habit, masticatory function and genetic inheritance can effect jaw size and facial growth. In an animal study, Yamada and Kimmel ${ }^{15}$ reported that diet and masticatory function had a direct relationship with craniofacial growth, specifically effecting the mandible, which could in turn affect the presence/ agenesis of third molar.

Prevalence of third-molar agenesis was more in skeletal class I malocclusion followed by class II and III which was not in accordance with Celikoglu, ${ }^{6}$ who reported that the prevelance of third molar agenesis was more in skeletal class III followed by class I and II, this may be due to polygenetic inheritance on formation of third molar germs that control maxillary and/or mandibular dimensions which was different in different 
population. Present study also shows that skeletal Class I malocclusions had more dental anomalies followed by class III and class II malocclusion which was stastically significant.

\section{CONCLUSION}

Prevalence of third-molar agenesis was more in skeletal class I malocclusion followed by class || and III but skeletal Class I malocclusions had more dental anomalies followed by class III and class II malocclusion.

\section{OJN}

\section{REFERENCES}

1. Sánchez MJ, Vicente A, Bravo LA. Third molar agenesis and craniofacial morphology. The Angle orthodontist. 2009;79(3):473-8.

2. Endo T, Ozoe R, Yoshino S, Shimooka S. Hypodontia patterns and variations in craniofacial morphology in Japanese orthodontic patients The Angle orthodontist. 2006;76(6):996-1003.

3. Yüksel S, Üçem T. The effect of tooth agenesis on dentofacial structures. The European Journal of Orthodontics. 1997;19(1):71-8.

4. Golovcencu L, Scripcaru C, Zegan G. Third molar development in relation to chronological age in Romanian children and young adults. Rom J Leg Med. 2009;17:277-82

5. Garn S, Lewis A, Vicinus J. Third molar agenesis and reduction in the number of other teeth. Journal of Dental Research. 1962;41 (3):717-

6. Celikoglu M, Kamak H. Patterns of third-molar agenesis in an orthodontic patient population with different skeletal malocclusions. The Angle Orthodontist. 2011;82(1):165-9.

7. Gravely JF. A radiographic survey of third molar development. British dental journal. 1965;119(9):397.

8. Zhu J, Marcushamer M, King D, Henry R. Supernumerary and congenitally absent teeth: a literature review. The Journal of clinical pediatric dentistry. 1996;20(2):87.

9. Winter G. Hereditary and idiopathic anomalies of tooth number, structure and form. Dental Clinics of North America. 1969;13(2):355-73.

10. Sperber G. Fabricating a face: the essence of embryology in the dental curriculum. Journal of dental education. 2003;67(3):370-4.

11. Nambiar P. Age estimation using third molar development. Malaysian Journal of Pathology. 1995;17:31-4.

12. Dr. Kuldeep Singh DRKG, Dr.Vipin Bharti. Age estimation from eruption of permanent teeth. Jiafm. 2005;27(4):0971-3.

13. Abe R, Endo T, Shimooka S. Maxillary first molar agenesis and other dental anomalies. The Angle Orthodontist. 2010;80(6):1002-9.

14. Ochoa BK, Nanda RS. Comparison of maxillary and mandibular growth. American journal of orthodontics and dentofacial orthopedics. 2004; 125(2):148-59.

15. Yamada K, Kimmel DB. The effect of dietary consistency on bone mass and turnover in the growing rat mandible. Archives of Oral Biology. 1991;36(2):129-38. 